\title{
O professor coordenador pedagógico nas escolas estaduais paulistas: da articulação pedagógica ao gerenciamento das reformas educacionais*
}

Maria José da Silva Fernandes

Universidade Estadual Paulista "Júlio de Mesquita Filho"

\section{Resumo}

Este artigo apresenta os principais resultados de uma pesquisa concluída que teve como objeto de estudo a função de coordenação pedagógica na rede estadual paulista, com destaque para o trabalho do professor coordenador pedagógico (PCP). A partir de um estudo bibliográfico-documental, analisamos as principais resoluções publicadas pela Secretaria de Estado da Educação de São Paulo no período de 1996 a 2010. Para a definição do período de análise, foram consideradas as sucessivas medidas educacionais de natureza neoliberal ocorridas na referida rede de ensino. A partir das resoluções selecionadas, foram estabelecidas algumas categorias de análise relacionadas à função: denominação, justificativa e atribuições legais; requisitos necessários para os professores coordenadores e critérios de escolha; avaliação do trabalho realizado e bibliografia básica solicitada nos processos seletivos. A análise dos documentos legais permite identificar a apropriação da função pelas reformas educacionais recentes, reconhecendo as implicações para o trabalho docente e para a organização da escola. Influenciadas por princípios gerencialistas e performáticos, as reformas educacionais promoveram profundas alterações na natureza do trabalho do professor coordenador pedagógico, o qual, de articulador no âmbito da escola, passou a ser legalmente o sujeito responsável pela disseminação das medidas oficiais e pelo controle das atividades docentes.

\section{Palavras-chave}

Contato:

Maria José da Silva Fernandes

mjsfer@fc.unesp.br

* Este artigo deriva de pesquisa financiada pela Fundação de Amparo à Pesquisa do Estado de São Paulo (FAPESP) no período de 2006 a 2008.
Coordenação pedagógica - Reformas educacionais - Gestão escolar. 


\title{
The teacher-pedagogical coordinator in São Paulo state schools: from the pedagogical articulation to the management of educational reforms*
}

\author{
Maria José da Silva Fernandes \\ Universidade Estadual Paulista "Júlio de Mesquita Filho"
}

Contact:

Maria José da Silva Fernandes mjsfer@fc.unesp.br

* This article derives from research sponsored by the Foundation for Research Support of the State of São Paulo (FAPESP).

\begin{abstract}
This article presents the main results of a completed research that had at its object the post of pedagogical coordination in the São Paulo state school system, emphasizing the work of the teacherpedagogical coordinator (PCP). Based on a bibliographicaldocumental study, we have analyzed the main acts issued by the Secretariat for Education of the State of São Paulo in the period from 1996 to 2010. To define the period of analysis we considered the successive educational measures of a neoliberal nature that were put in place within the above-mentioned school system. From the selected acts, categories of analysis were established related to that post: denomination, justification and legal attributions; necessary requisites for teachers-coordinators and selection criteria; evaluation of the work conducted and basic bibliography requested at selection processes. The analysis of the legal documents allows us to identify the appropriation of this post by the recent educational reforms, recognizing the implications for the teaching work and for school organization. Inspired by managerial and performance principles, the educational reforms promoted deep changes in the nature of the work of the teacher-pedagogical coordinator, who, from an articulation agent within the school, began to be legally recognized as the subject responsible for the dissemination of official measures and by the control of teaching activities.
\end{abstract}

\section{Keywords}

Pedagogical coordination - Educational reforms - School management. 


\section{A coordenação pedagógica no contexto das reformas educacionais paulistas}

A elaboração de políticas educacionais definidas sob a influência de organismos internacionais, tais como o Banco Mundial, provocou, nas últimas décadas, grandes e profundas alterações no cotidiano das escolas. A rede estadual paulista, por exemplo, a maior do país, vivenciou a partir da segunda metade da década de 1990 a implantação sucessiva de medidas educacionais pautadas por princípios gerencialistas e performáticos que impactaram o trabalho docente e a organização escolar.

A performatividade, conceito-chave no contexto neoliberal,

é uma tecnologia, uma cultura e um método de regulamentação que emprega julgamentos, comparações e demonstrações como meio de controle, atrito e mudança. (BALL, 2005, p. 543)

0 mesmo autor afirma que o gerencialismo é um mecanismo de reengenharia, de reconstrução do setor público que passou, a partir das reformas, a conhecer novas orientações, novas relações de poder e novas opções de direcionamento das políticas sociais. Associado à performatividade, o gerencialismo

desempenha o importante papel de destruir os sistemas ético-profissionais que prevaleciam nas escolas, provocando sua substituição por sistemas empresariais competitivos. (p. 544)

Os elementos do gerencialismo e da performatividade foram observados nas recentes e diferentes medidas educacionais paulistas. Pesquisas como as realizadas por Fernandes (2008), Rodrigues (2010), Cação e Mendonça (2011) e Barbosa (2011) identificaram e analisaram os desdobramentos de tais elementos nas questões curriculares, organizacionais e de carreira docente no Estado de São Paulo. Por meio de medidas diversas, as reformas provocaram mudanças técnico-estruturais nas escolas, tais como a reorganização física da rede, a implantação da progressão continuada e o pagamento do bônus mérito. De acordo com Ball (2002), medidas como essas também alteraram a relação dos docentes com o próprio trabalho, já que elas preveem a reforma dos profissionais do setor público via introdução de elementos de controle e regulação, no caso dos professores, alguns mais explícitos, como as avaliações externas, e outros mais sutis que permearam o cotidiano via retórica discursiva, tais como a responsabilização.

As mudanças provocadas no campo educacional não ocorreram de forma rápida e tampouco desarticulada. Há quase duas décadas, um mesmo partido mantém-se no poder em São Paulo; dessa forma, as medidas educacionais implementadas foram parte de um amplo projeto de reestruturação baseado na reforma do Estado que introduziu medidas de diferentes naturezas e profundidades na rede de ensino. De acordo com Ball (2005), as reformas baseadas no gerencialismo tiveram essa característica já que, em vez de realizar "uma mudança de uma vez por todas", apresentaram "mudanças incrementais maiores e menores, mudanças essas em grande número" (p. 545).

Ao analisar as reformas recentes, notamos que as primeiras grandes alterações chegaram às unidades escolares via Escola de Cara Nova (SÃO PAULO, 1996a), projeto que incluiu, em um amplo espectro, alterações que envolveram desde os aspectos pedagógicos e organizacionais até a gestão dos recursos financeiros pelos agentes escolares, iniciativas fundadas no que Ball (2002) denominou gestão baseada no local. Tal qual o ideário tecnicista, as medidas implementadas deixaram os docentes num plano secundário, embora no plano do discurso tenham defendido a autonomia e a iniciativa das escolas. A partir do projeto Escola de Cara Nova, os elementos iniciais da reforma foram complementados por medidas posteriores que 
se estenderam, com diferentes denominações até o momento atual, consolidando um conjunto de medidas bem articuladas do ponto de vista do planejamento.

Dentre a série de mudanças vivenciadas pelos docentes paulistas, detivemo-nos na expansão da função de professor coordenador pedagógico (PCP), pois esta se tratou de objeto central na pesquisa que realizamos. Tal função, a partir da Resolução $n^{\circ}$ 28/96, passou a estar presente em todas as unidades escolares com mais de dez classes em funcionamento, em acordo com o artigo $\mathrm{n}^{\circ} 21$ da Lei $\mathrm{n}^{\circ} 444 / 85$ (SÃo PAULO, 1985). Nesse sentido, a expansão da função no âmbito da reforma educacional atendeu, contraditoriamente, às reivindicações dos movimentos docentes organizados que há vários anos defendiam a criação da função de coordenação como parte da carreira aberta e não como cargo na estrutura da rede estadual.

De acordo com os documentos oficiais que apresentaram os elementos normativos da Escola de Cara Nova, o PCP deveria ser responsável pelo trabalho de articulação das ações pedagógicas e didáticas realizadas nas escolas e pelo subsídio ao professor no desenvolvimento das ações docentes, além de atuar no fortalecimento da relação entre escola e comunidade e na melhoria do processo de ensino-aprendizagem (SÃO PAULO, 1996b).

Escolhidos pelos pares, os PCPs passaram a compor a equipe gestora das escolas, ampliando as experiências pontuais e positivas anteriormente ocorridas com a coordenação, quando esta esteve vinculada a projetos específicos e/ou experimentais da Secretaria de Estado da Educação de São Paulo, como foi o caso das escolas experimentais, dos ginásios vocacionais e das escolas de aplicação, nas décadas de 1950 e 1960; do ciclo básico, do projeto noturno e do CEFAM $^{1}$, na década de 1980; e da escola padrão, na década de 1990. Em todos os casos citados, a coordenação pedagógica apresentou-se como uma função que contribuiu para a realização de

1- Centros Específicos de Formação e Aperfeiçoamento do Magistério. práticas inovadoras que contaram com a atuação ativa dos agentes escolares, como discutido por Fusari (1997), Almeida (1998), Tamberlini (2001) e Tamara Oliveira (2003).

Os estudos realizados por Teixeira (1988) e Fernandes (2004) indicaram que, desde meados da década de 1970, ocorreram em São Paulo reivindicações organizadas pelos movimentos docentes para garantir nas escolas a presença de professores responsáveis pela articulação do trabalho pedagógico. Por conta disso, a Resolução no 28/96 foi uma medida reformista bem-vinda e comemorada pelos docentes e gestores. Em documento publicado pelo maior sindicato dos professores no Estado, a APEOESP, a função foi destacada como uma conquista indiscutível da categoria, muito embora o mesmo documento tenha apontado a função como fonte de novas responsabilidades e preocupações, pois, já adiantava o sindicato, não bastava a presença formal dos PCPs nas escolas para ocorrer a tão desejada articulação pedagógica (SÃO PAULO, 1996c). Além disso, a preocupação justificava-se pela ausência da participação docente nos processos de definição das medidas reformistas.

A incorporação da função de coordenação pedagógica nas reformas dos anos 1990 ocorreu em meio a medidas que foram decididas à revelia dos professores, que, sem participação, foram apenas comunicados sobre as alterações vivenciadas pelas escolas. De acordo com Barroso (2006), essa foi uma prática comum nas reformas educacionais em diferentes paises do mundo, pois os elaboradores de politicas apresentavam uma crença no fato de que as regulações institucionais, ao serem impostas às escolas, seriam aceitas pelos sujeitos, havendo adesão local ao modelo imposto. Nessa perspectiva, desconsiderou-se o papel ativo dos sujeitos nos processos de regulação, notadamente na regulação interna, definida por Barroso et al. (2006) como os processos formais e informais que, contando com a participação dos diversos atores sociais, asseguraram o funcionamento das escolas. 
As políticas, nessa perspectiva vertical com ações e medidas decididas pelo governo estadual e executadas pelas escolas, foram comunicadas às unidades escolares e a seus docentes a partir do início do ano de 1996. A exclusão dos docentes nas discussões contrariou o importante movimento de democratização do ensino que se havia iniciado na década anterior no Estado de São Paulo e que estava ainda em vias de fortalecimento e construção social.

Sem a participação dos professores, as reformas e seus diferentes elementos foram conhecidos por meio das diversas publicações oficiais utilizadas para traduzir o embasamento teórico-prático do modelo administrativo. As publicações oficiais compostas inicialmente por livretos do projeto Escola de Cara Nova (SÃO PAULO, 1995) encontraram na recém criada Hora de Trabalho Pedagógico Coletivo (HTPC), organizada pelos também recém designados professores coordenadores pedagógicos, espaço propício para penetração no cotidiano docente, o que não significou, obviamente, aceitação total ou adesão às ideias apresentadas. A partir desse momento, a função, associada a outras medidas reformistas, passou a ter participação importante na disseminação das políticas oficiais, justificando a preocupação anteriormente apresentada pelo sindicato dos professores, quando este apresentou dúvidas quanto à finalidade da criação da função no âmbito das reformas.

Ao analisar os documentos oficiais que a partir daí deram sustentação formal às reformas educacionais, identificamos a presença de um discurso bastante convincente nos textos publicados, principalmente porque estes incorporaram várias bandeiras progressistas defendidas pelos professores, tais como a gestão democrática, o trabalho coletivo e a autonomia das escolas. Porém, observou-se também o hibridismo apresentado por Barroso (2006) como característica das reformas educacionais que, ao relativizarem as diferenças conceituais, apresentaram conjuntamente nos documentos propostas baseadas em modelos bipolares, tais como centralização/descentralização, público/ privado, autonomia/regulação. Como afirmou Ball (2005), ao serem apropriados em contextos diversos daqueles em que se originaram, os conceitos foram alterados em forma e significado.

A partir da Escola de Cara Nova, a rede conheceu dois outros projetos governamentais: Escola do Acolhimento e São Paulo faz Escola. De maneira geral, esses projetos lançaram medidas que complementaram e intensificaram a gestão gerencialista e performática no interior das escolas. A já iniciada política de avaliação do desempenho das escolas e dos professores, por exemplo, foi aprimorada e passou a fazer parte do cotidiano dos professores, definindo padrões de conduta e de trabalho dentro das escolas. As novas políticas pautaram a definição curricular, os projetos e até a própria formação continuada dos professores. Apoiando-se em Ball (2002), podemos dizer que a competição, a eficiência e a produtividade introduzidas na rede trouxeram novas formas de disciplina e novos sistemas éticos nas escolas, favorecendo o controle docente e o enquadramento ao modelo administrativo proposto. A autonomia, por exemplo, ganhou outro significado nesse contexto e, contraditoriamente, passou a justificar a dimensão individual do trabalho em detrimento da organização coletiva como aprendizagem social e política.

Entre 1996 e 2010, período considerado neste artigo, alguns elementos e mecanismos decorrentes das reformas desapareceram, como as salas ambientes, os projetos de correção de fluxo, as ações voltadas ao protagonismo juvenil e as recuperações de férias. Em outros casos, houve a permanência das medidas reformistas, mas com alterações bastante significativas em sua constituição e em seus objetivos iniciais. A partir dos estudos realizados, podemos afırmar que esse foi o caso da coordenação pedagógica, objeto central do presente artigo. Diferentemente de outras medidas criadas no âmbito das reformas, a função de PCP permaneceu ao longo dos anos; porém, não por acaso, passou por grandes mudanças do ponto de vista legal que alteraram as atividades realizadas e a 
natureza da função, aprimorando a dimensão empresarial do trabalho docente.

Com o objetivo de apresentar e discutir mais detalhadamente as mudanças legais relativas ao trabalho da função de PCP, analisamos as principais resoluções publicadas no período supracitado, bem como suas implicações para a organização escolar. A Resolução SE n 28/96 (SÃO PAULO, 1996b) apresentou as exigências legais para a designação de professores para exercer a função de coordenação pedagógica que, de maneira bastante genérica, estava anteriormente prevista nos estatutos paulistas (leis estaduais $\mathrm{n}^{\text {os }} 114 / 74,201 / 78$ e 444/85). Apesar da previsão legal anterior, a função havia saído pontualmente do papel com os já referidos projetos especiais citados neste artigo.

A partir dessa primeira Resolução, lançada no auge das reformas educacionais da década de 1990, a SEE/SP publicou, nos anos posteriores, outros documentos normativos complementares que apresentaram disposições legais sobre a função gratificada de professor coordenador. A sequência de resoluções - 28/1996, 76/1997, 35/2000, 66/2006, 88/2007, 90/2007 e 53/2010 - alterou as regras e os rumos da coordenação pedagógica nas escolas, impondo aos ocupantes da função atribuições diferentes daquelas inicialmente apresentadas e partilhadas pelos professores ao longo dos anos.

\section{As alterações na função de coordenação pedagógica no âmbito das reformas educacionais}

Imbuídos da certeza de que a legislação explicitou posições políticas e ideológicas, estabelecemos o conjunto supracitado de resoluções como objeto de análise. A partir desse corpus, identificamos e analisamos os principais aspectos relativos ao trabalho da coordenação pedagógica, bem como as implicações das alterações legais para a organização escolar e para o trabalho docente. Durante a análise legal-documental, estabelecemos algumas categorias centrais que foram exploradas ao longo do estudo, dentre as quais se destacaram: denominação da função e suas atribuições legais; justificativas para a existência da função; requisitos necessários para os ocupantes da função; processo de seleção dos professores coordenadores pedagógicos; avaliação do trabalho realizado na função; e bibliografia básica solicitada nos processos seletivos periódicos organizados pela SEE/SP.

Um primeiro aspecto que nos chamou a atenção em relação à função foi a própria denominação a ela atribuída nas resoluções. Inicialmente, o docente era designado para o exercício da função de professor coordenador pedagógico $\left(\mathrm{PCP}^{2}\right)$; a partir da Resolução $\mathrm{n}^{\circ}$ 35/2000, tal função passou a ser denominada apenas professor coordenador (PC). A supressão do termo pedagógico não foi uma alteração pequena e insignificante, como já apontado nos estudos de Duarte (2007) e Fernandes (2008). Com a ausência do termo, excluiu-se um elemento central de identidade da função que, ainda recente do ponto de vista da abrangência na rede, estava em processo de profissionalização e de reconhecimento nas escolas.

Estudos anteriores realizados por Diasda-Silva e Lourencetti (2002), Clementi (2001), Mate (1998), Christov (2001) e Fernandes (2008) indicaram, a partir de resultados de pesquisas empíricas realizadas direta ou indiretamente com PCPs, que a função apresentava identidade frágil e espaço de atuação escolar pouco definido, ou seja, ela carecia, no cotidiano, de um território de atuação marcadamente pedagógico. Sem o pedagógico como importante referência de atuação, a função passou a ser identificada, em muitos casos, como aquela que poderia coordenar qualquer coisa no interior das escolas, desviando a atenção do foco principal do trabalho para as inúmeras tarefas cotidianas presentes em escolas marcadas pela sobrecarga de tarefas, pela intensificação docente (OLIVEIRA,

2- Pela importância do termo pedagógico na constituição da função, utilizaremos ao longo do texto a denominação PCP, mesmo após as alterações legais. 
D., 2003) e pelas urgências e emergências do cotidiano (CHRISTOV, 2004).

A partir de pesquisa realizada com coordenadores pedagógicos de escolas do interior paulista, Fernandes (2008) identificou uma série de difıculdades para que os PCPs realizassem as tarefas de articulação, formação e apoio docente. No dia a dia, a função perdia-se no emaranhado de demandas apresentadas pelas escolas. 0 cotidiano de trabalho era repleto de atividades, mas elas eram difusas e emergenciais.

Com a ausência do reconhecimento legal de que a coordenação era uma função de natureza pedagógica, institucionalizou-se a atuação do PCP em outras e variadas tarefas que não correspondiam ao necessário e devido campo de atuação do coordenador. Estudos realizados por Mate (1998), Clementi (2001), Christov (2001), Franco (2000), Guilherme (2002), Duarte (2007) e Fernandes (2009) demonstraram que os professores ocupantes da função realizavam um trabalho marcado por muitas dificuldades, várias delas relacionadas ao não reconhecimento de sua importância e de suas atribuições. Dentre as dificuldades cotidianas apontadas pelos estudos citados, destacaram-se a realização de tarefas burocráticas, a disseminação de projetos e propostas oficiais e o cumprimento de múltiplas atividades destinadas a outros sujeitos escolares - o já conhecido desvio de função. Nas pesquisas, apareceram várias referências ao trabalho do PCP como apagador de incêndios, o que pode ter sido intensificado a partir das mudanças legais.

Alterações significativas foram identificadas também nos objetivos e nas justificativas legais apresentadas para a existência da função na rede estadual. Inicialmente, a função justificava-se por sua importância na realização de ações voltadas para a articulação do trabalho coletivo e para a construção do projeto político pedagógico (Resolução $n^{\circ}$ 28/1996), aproximando-se do ideário progressista que via na função uma possibilidade de fortalecimento da gestão escolar democrática. Como apontado por Russo (2011), a coordenação é uma prática específica no âmbito da gestão que se contrapõe ao modelo burocrático e autoritário de administração. Posteriormente, a coordenação passou a ser apresentada como um dos "pilares estruturais da atual política de melhoria da qualidade do ensino" (Resolução n ${ }^{0}$ 88/2007), e os professores responsáveis pela função identificados como "gestores implementadores das políticas ofıciais” (Resolução n 53/2010), afinando-se a função do ponto de vista legal aos propósitos gerenciais e performáticos das reformas educacionais recentes.

Guilherme (2002), mesmo antes da publicação das resoluções citadas, já havia afirmado que os PCPs eram cobrados por ações relacionadas à veiculação, à imposição e à defesa de projetos da SEE/SP:

Percebi, nessa convivência, o quanto o coordenador era responsável pela atuação dos professores, pela transmissão de propostas oficiais e que ficava no meio de uma relação, era o intermediário entre 0 professor e o supervisor de ensino. Isto é, nas tramas da escola um era considerado como o executor (professor), o outro como transmissor de propostas (coordenador) e outro ainda como regulador-cobrador das leis e decretos (supervisor). (p. 77)

Da ação articuladora e do papel central ocupado no aprimoramento do processo de ensino-aprendizagem nas unidades escolares (resoluções n ${ }^{\text {os }}$ 28/1996 e 76/1997), os PCPs passaram a cuidar da otimização dos recursos e das parcerias entre escola e comunidade (Resolução no 35/2000). Mais recentemente, com a publicação das resoluções $n^{\text {os }} 88 / 2007$ e 90/2007, os PCPs passaram a ser responsabilizados pela elevação dos níveis de desempenho escolar expressos nos resultados das avaliações externas. Tornaram-se responsáveis também pelo monitoramento das avaliações escolares e pelas ações de intervenção na prática docente, buscando promover o desenvolvimento das escolas com vistas à eficácia e à melhoria do trabalho. Essas novas exigências, que apareceram 
mescladas ao discurso da autonomia e da capacidade da escola de buscar soluções para seus problemas, podem ser interpretadas a partir dos estudos de Ball (2002) sobre as tecnologias políticas presentes na performatividade:

As responsabilidades da gestão são delegadas e o espírito de iniciativa e a capacidade de resolver problemas são altamente valorizados. Por outro lado, são implementadas novas formas de vigilância imediata e de auto-monitorização, por exemplo, os sistemas de avaliação/apreciação, definição de metas/objectivos, comparação de rendimentos/produção. (p. 9)

A análise das justificativas legais apontou para a ampliação considerável da responsabilização dos PCPs em relação aos resultados de desempenho apresentados pelas escolas, indicando mais claramente a atuação dos mesmos como gerentes das reformas educacionais. Assim, o trabalho passou a ter um foco menor nas necessidades e no desenvolvimento da escola e maior no monitoramento do trabalho docente, nas intervenções nas práticas docentes e na transmissão, na implementação e no acompanhamento das políticas estaduais, intensificando tanto o próprio trabalho do PCP quanto o realizado pelos docentes. Como discutido por Ball (2002), esse tipo de atuação "consome tanta energia, que reduz drasticamente a energia disponível para se fazerem melhoramentos, para se evoluir" (p.12). Segundo Cação e Mendonça (2011), após estudarem as recentes políticas educacionais paulistas, isso ocorreu porque as reformas secundarizaram os aspectos pedagógicos em relação aos aspectos administrativos.

Em estudo voltado para a análise do programa São Paulo faz Escola, Rodrigues (2010) identificou o papel de monitoramento dos PCPs junto aos professores dos anos iniciais, monitoramento que ele classificou como direto ou indireto, mas como cerceador da autonomia docente:

Uma vez por semana os professores coordenadores passaram a receber orientações elaboradas pela SEE através de reuniões semanais na Diretoria de Ensino. Após as reuniões os professores coordenadores repassam aos professores, através das HTPC, a formação recebida. Se por um lado a reunião coletiva passa a ter mais discussões e troca de experiências, o que pode ser considerado um ponto positivo, por outro, todas as discussões e orientações caminham unilateralmente no sentido de que sejam colocadas em prática as orientações e projetos desenvolvidos pela SEE, o que pode significar impositividade e cerceamento da autonomia docente. (p. 148)

As novas atribuições que foram destinadas aos PCs e que serviram para justificar legalmente a função no âmbito das reformas foram bem distintas das atividades esperadas pelos professores e pelos movimentos docentes organizados, já que estes reivindicaram ao longo dos anos a presença de um parceiro e articulador pedagógico na escola, o que de fato ocorreu nas experiências inovadoras e progressistas que tiveram a participação da coordenação. De acordo com documentos do próprio sindicato (SÃO PAULO, 1996c) e dos estudos de Teixeira (1988), dentre as reivindicações docentes do final dos anos 1970 e início dos anos 1980, estiveram aquelas voltadas para a alocação de um profissional que desempenhasse a ação supervisora no interior da escola, objetivando o fortalecimento do trabalho coletivo e a reflexão sobre as práticas pedagógicas. Nesse sentido, identificou-se nas resoluções um distanciamento entre o esperado e o ocorrido.

Ao analisar as duas últimas resoluções - 88/2007 e 53/2010 -, verificamos que elas apontaram mais claramente para a atuação da função como responsável por incutir no cotidiano escolar a cultura do envolvimento pessoal e a preocupação com a eficácia e a eficiência das escolas nas avaliações externas, o que pode ser exemplificado a partir do excerto de entrevista apresentado no trabalho de Fernandes (2008): 
É uma loucura, porque você é obrigado a fazer para mostrar resultados, tem que fazer, a gente não tem autonomia nenhuma para falar não vamos fazer, para escolher o que a gente quer fazer. Eu acho isso um absurdo, você faz uma proposta pedagógica, define as ações, elabora os projetos, anualmente você faz os adendos, tudo isso vai para a Diretoria, lá alguém lê, homologa e devolve para a escola. Então esses projetos que já estão previstos e homologados é que deveriam ser prioritários porque saíram da própria escola, eles foram definidos em cima de necessidades que a equipe identificou, eles deveriam ser privilegiados em cima dos projetos que vem lá de cima e que ninguém sabe quem definiu. É uma loucura e eu acho que é uma falta de respeito enorme com o trabalho da escola, com o trabalho do professor. 0 pior é que na hora de computar os projetos que contam para o bônus ou para a avaliação da escola, o que a gente faz não conta nada, conta os projetos deles, os projetos que eles mandaram. Aí, como tudo vira bônus, o coordenador cobra os resultados. (p. 227)

Além disso, a pesquisa de Rodrigues (2010) indicou aspectos relacionados ao controle do trabalho e às intervenções nas práticas docentes. No cotidiano, tornaram-se comuns as entradas em salas de aula para verificação e adequação da metodologia e dos conteúdos ensinados à proposta pedagógica do Estado, o preenchimento de cadernos de bordo com o acompanhamento docente e as avaliações das ações cotidianas, apontando mais para uma atuação de inspeção e supervisão no sentido clássico da administração do que de parceria e apoio pedagógico.

Alterações legais significativas foram observadas também no processo de escolha dos ocupantes da função. A Resolução nº 28/1996 estabeleceu que os PCPs deveriam ser escolhidos pelo grupo de professores mediante avaliação das propostas de trabalho dos interessados em exercer a função, considerando que esta deveria corresponder às necessidades específicas da escola. A partir da decisão do grupo de professores, o Conselho de Escola, estabelecido legalmente em São Paulo desde 1985, ratificava a decisão tomada coletivamente. Tal forma de escolha manteve-se até meados dos anos 2000, quando a publicação da Resolução n 35 alterou as regras para seleção dos PCs (a partir daí, com a nova denominação), que passou a ser responsabilidade apenas dos membros do Conselho de Escola. Apesar disso, podemos considerar que a forma de escolha ainda era calcada em princípios democráticos, uma vez que os professores faziam-se representados por seus pares nos Conselhos, o que de certa forma garantia que as demandas escolares fossem a base para a definição do perfil do PCP.

Com a publicação da Resolução $\mathrm{n}^{\circ}$ 66/2006 ampliou-se a participação dos diretores na escolha dos PCs e estes passaram a ter maior atuação na definição dos critérios de seleção para a escolha dos ocupantes da função. A participação dos diretores nesse processo foi o primeiro agravo à relação democrática que estava estabelecendo-se e fortalecendo-se nas escolas desde a publicação da Resolução $n^{0}$ 28/96. A possibilidade legal de intervenção do diretor nos critérios de seleção reduziu a participação docente num importante processo de tomada de decisão e de discussão do projeto de escola. Tal fato comprometeu a articulação do trabalho coletivo e a corresponsabilidade docente na composição da equipe gestora. Além disso, é preciso considerar a presença de disputas de poder e território de atuação nas unidades escolares que as pesquisas de Clementi (2001), Mate (1998) e Dias-da-Silva e Lourencetti (2002) já denunciavam antes mesmo das alterações legais; em tais disputas, o diretor detentor de um cargo e de uma autoridade legalmente estipulada contrapunha-se à função do PCP, visivelmente marcada pela autoridade conquistada e partilhada com os docentes (FERNANDES, 2009). 
As resoluções posteriores - 88/2007, 90/2007 e 53/2010 - foram ainda mais explícitas na alteração dos critérios de escolha e designação dos PCs, já que negaram totalmente a participação docente nesse processo. A responsabilidade pela definição dos ocupantes da função passou a ser perigosamente centralizada nas mãos do diretor e do supervisor de ensino ${ }^{3}$ responsável pela unidade escolar. A atuação mais incisiva do supervisor, cargo conhecido historicamente no Estado de São Paulo pelo distanciamento físico e pedagógico em relação às questões cotidianas das escolas, havia sido apontada pelas reformas como uma das medidas necessárias para a implementação e o acompanhamento das ações oficiais programadas (SÃO PAULO, 2007a). Conjuntamente, de acordo com os documentos oficiais, supervisores, diretores e PCPs seriam os responsáveis pelo monitoramento e pela gestão local das reformas.

A alteração na forma de escolha dos PCPs foi significativa no sentido de apontar os novos rumos das políticas educacionais implementadas na rede estadual paulista, indicando o distanciamento dos órgãos centrais e dos gestores escolares em relação às necessidades e aos desejos docentes. Do ponto de vista da gestão democrática tal fato foi grave, já que a escolha do coordenador constituiu-se num dos raros momentos em que a voz (GIROUX, 1997) e a decisão docente eram consideradas. A participação docente proporcionou o aprimoramento das relações democráticas e o fortalecimento do trabalho coletivo, bem como o surgimento de novas e ricas formas de gestão escolar marcadas pela partilha de poderes. Do ponto de vista da atuação docente, a participação na escolha dos PCPs foi um embrião da democratização das relações de trabalho no interior das unidades escolares.

Acompanhando as alterações no processo de escolha dos PCPs, observamos que este teve relação com a ampliação do controle

3- № Estado de São Paulo, a supervisão é um cargo lotado nas Diretorias Regionais de Ensino, e os supervisores são responsáveis pelo acompanhamento das atividades pedagógicas em várias unidades escolares ligadas às DEs. externo sobre as escolas, favorecendo a concentração de poderes nas mãos daqueles que hierarquicamente tinham uma posição superior na organização do sistema educacional e que, muitas vezes, no trabalho cotidiano, manifestavam traços e ranços herdados de uma administração escolar burocratizada e centralizadora. As três últimas resoluções - 88/2007, 90/2007 e 53/2010 - apontaram os PCs como responsáveis por acompanhar, monitorar e zelar pela eficácia das novas medidas implementadas. Dessa forma, podemos dizer que o trabalho docente passou a ser regulado e controlado pelo diretor e pelo supervisor com o apoio dos professores coordenadores pedagógicos, que, na perspectiva gerencialista e performática, foram apontados como "os responsáveis pela melhoria dos padrões de qualidade apresentados pelas escolas" (SÃO PAULO, 2007b).

Dada a proximidade com o trabalho dos professores, os PCPs passaram a ser, teoricamente, os olhos visiveis do sistema educacional. Nessa perspectiva, o trabalho dos coordenadores passou a facilitar "o papel de monitoramento do Estado, que governa à distância - governando sem governo" (BALL, 2005, p. 548). Nesse trabalho, "a base de dados, a reunião de avaliação, a análise anual, a elaboração de relatórios, a publicação periódica dos resultados, as inspeções e análise dos pares” (p. 548) foram importantes mecanismos da performatividade.

Num claro movimento de controle e monitoramento das escolas, as reformas gerencialistas e performáticas apropriaram-se da função, reduzindo até mesmo os espaços que tradicionalmente eram marcados pela autonomia e pela atuação ativa dos PCPs. As HTPCs, por exemplo, espaços de atuação privilegiada dos ocupantes da função, passaram a ser organizadas em torno dos materiais elaborados pela SEE/SP. A partir de 2007, os coordenadores passaram a utilizar (quase obrigatoriamente) como base para as reuniões coletivas o Caderno do Gestor (SÃO PAULO, 2007a), espécie de manual oficial de trabalho que apresentava desde as temáticas que deveriam ser abordadas nas escolas até a 
definição do tempo para as atividades e a duração da pausa para o café durante os encontros. o Caderno do Gestor, parte dos documentos que compunham a Proposta Curricular do Estado de São Paulo (SÃO PAULO, 2007c), desconsiderou tanto a importância do exercício da autonomia docente no planejamento das ações pedagógicas, quanto as necessidades específicas de cada unidade escolar nesse processo. Na Proposta, o PCP era identificado como "líder e animador da implementação dessa proposta curricular nas escolas" (SÃo PAULO, 2008).

As atribuições legais da função de PC também sofreram alterações nas diferentes resoluções. Inicialmente genéricas, as tarefas foram tornando-se mais detalhadas e direcionadas ao cumprimento das determinações oficiais. A análise realizada permitiu-nos afırmar que, nas resoluções de 1996 e 1997, as atribuições eram difusas e pouco detalhadas, porém eram tarefas complexas do ponto de vista do trabalho pedagógico, já que aos PCPs cabia, dentre outras coisas, assessorar a direção da escola na articulação das ações pedagógicas e didáticas; subsidiar o professor no desenvolvimento de seu trabalho e em sua formação, e favorecer e organizar os momentos de reflexão coletiva.

A partir do ano 2000, as resoluções publicadas detalharam mais as atribuições do PCPs e eles passaram a ser cobrados pelo acompanhamento dos projetos desenvolvidos pelas escolas, normalmente definidos verticalmente e realizados sob condições de trabalho adversas (SAMPAIO; MARIN, 2004), pela orientação dos professores em relação aos referenciais teóricos defendidos pela SEE/SP, pelo desenvolvimento e pela análise dos referenciais de desempenho escolar, e pela ampliação da articulação entre escola e comunidade. Essas atribuições mais gerenciais do que de articulação podem ser interpretadas a partir de Ball (2005), que afirma que o trabalho do gerente perante as escolas envolve

incutir uma atitude e uma cultura nas quais os trabalhadores se sentem responsáveis e, ao mesmo tempo, de certa forma pessoalmente investidos na responsabilidade pelo bem da organização. (p. 545)

Outra categoria de análise referiu-se à avaliação do trabalho dos professores que ocupavam a função de PCP. Nas resoluções $n^{\text {os }}$ 28/1996, 76/1997 e 35/2000, a avaliação anual era responsabilidade dos docentes que atuavam nas escolas e de seus respectivos conselhos, constituindo-se num importante momento de troca e de reflexão não apenas sobre o trabalho em si, mas sobre o projeto pedagógico da escola (DUARTE, 2007). A partir de 2006, a avaliação passou a ter a presença incisiva do diretor, reduzindo a participação do grupo de professores e dos demais segmentos da escola no processo.

As resoluções publicadas após 2007 explicitaram claramente o controle externo em relação à função. Sem a possibilidade de participação dos professores e do Conselho de Escola, a avaliação concentrou-se nas mãos dos diretores e supervisores, que passaram a ser responsáveis por julgar os PCPs a partir do cumprimento das atribuições legais que, como já discutido aqui, tornaram-se menos pedagógicas e mais gerenciais. Nesse sentido, o Conselho de Escola perdeu sua natureza deliberativa. Na correlação de forças, a avaliação dos diretores e supervisores se sobrepôs às necessidades das escolas e dos professores, negando a participação coletiva nos processos decisórios. A negação da participação coletiva evidenciou a eminência de uma autonomia decretada e falaciosa que se contrapôs à autonomia como processo de construção social (BARROSO, 1998).

Também mereceu destaque na análise que realizamos a bibliografia indicada para os processos seletivos de PCPs. As resoluções $\mathrm{n}^{\text {os }}$ 28/96 e 76/97, embora divulgadas no auge do projeto Escola de Cara Nova, apresentaram uma bibliografia formada basicamente por materiais e textos institucionais, muitos deles publicados em anos anteriores às reformas e decorrentes da abertura e democratização das escolas públicas paulistas. Dentre as temáticas, 
destacaram-se a construção do projeto político pedagógico, a importância do trabalho coletivo, a necessidade da formação continuada e do planejamento de ensino, além de discussões sobre as questões curriculares, a organização do trabalho docente e a avaliação escolar, temáticas estas importantes em um momento de implantação dos ciclos de aprendizagem e de estabelecimento das HTPCs nas escolas. As temáticas e a bibliografia apresentada eram condizentes com o papel articulador dos PCPs.

No ano 2000, a bibliografia incluiu leis e documentos oficiais, dentre eles, a Lei de Diretrizes e Bases de 1996, as Propostas Curriculares do Estado de São Paulo que haviam sido publicadas na década de 1980, os temas transversais abordados pelos PCNs, os manuais da Escola de Cara Nova (SÃO PAULO, 1996a) e materiais específicos sobre as classes de aceleração (projeto de adequação do fluxo que foi adotado pela SEE). A bibliografia tornou-se mais extensa e mais próxima às orientações gerais dos organismos internacionais aos países em desenvolvimento. Boa parte das obras sugeridas havia sido publicada no auge das políticas educacionais neoliberais, com destaque para as escritas pelos europeus que tiveram grande influência nas alterações curriculares brasileiras na década de 1990: Cesar Coll e Philippe Perrenoud.

Reconheceu-se na bibliografia uma explícita preocupação com a progressão continuada, com as novas tendências avaliativas, com a pedagogia das competências, com a educação para a empregabilidade e a equidade social. Identificou-se um misto de autores e temáticas - a epidemia politica abordada por Ball (2002). Segundo o referido autor, tal epidemia é sustentada por ideias disseminadas por

agentes poderosos, tais como o $\mathrm{BM}$ e a OCDE; atrai políticos de diferentes facções e está a implementar-se nos mundos assumidos de muitos educadores acadêmicos. (p. 3)
Dessa forma, observou-se que os anos 2000 foram um marco importante não só em relação às alterações na bibliografia dos PCPs, mas na focalização das políticas educacionais, que se tornaram mais afınadas com as tendências mundiais.

A resolução seguinte - $\mathrm{n}^{\circ}$ 88/2007 -, publicada no ínterim do programa São Paulo faz Escola, que se apresentou publicamente como a revolução da educação pública paulista (SÃO PAULO, 2007b), centrou esforços na questão curricular e isso se evidenciou nos textos, artigos e documentos relacionados na bibliografia para seleção dos PCPs. Dentre os documentos oficiais, destacaram-se o Caderno do Gestor e os documentos que compunham a nova Proposta Curricular do Estado de São Paulo. A nova proposta seguiu uma ordem diversa da vivenciada nos anos 1980, quando os professores da rede e as universidades estabeleceram parcerias para construir um novo currículo. A proposta dos anos 2000 derivou de um movimento vertical capitaneado pela SEE/SP que contou com baixa participação dos professores, o que Cação e Mendonça (2011) definiram como modelo burocrático de currículo. Além da Proposta, havia alguns autores referenciados na Resolução, destacando-se os que defendiam a pedagogia das competências, o desenvolvimento de projetos de ensino e os modelos flexíveis de gestão educacional, autores em consonância com as exigências do gerencialismo e da performatividade, ressaltando-se aqui a liderança escolar.

As alterações legais na função de PCP no período de 1996 a 2010 foram, dessa forma, parte de uma política educacional mais ampla. Assumida em novos contextos educacionais, a função desprendeu-se de seus objetivos e conceitos iniciais. Em todas as categorias analisadas, observou-se um movimento no sentido de torná-la menos articuladora e mais gerencial.

\section{Considerações finais}

As medidas que surgiram a partir do projeto Escola de Cara Nova reduziram as 
possibilidades de participação coletiva nas escolas, sendo que estas se fragilizaram como locus de trabalho e como espaço privilegiado de construção da autonomia, contradizendo o argumento retórico predominante nos discursos reformistas. Nesse contexto, a partir da análise das diversas resoluções e das categorias selecionadas, observamos que a função de professor coordenador pedagógico foi sendo vinculada à administração gerencialista e performática que, desde meados dos anos 1990, passou a fazer parte das políticas implementadas pelo governo paulista.

A função de PCP nos moldes reivindicados pelos professores com base em experiências progressistas anteriores realizava um trabalho bastante difícil, exigente e complexo. Ao assumir novas tarefas, a coordenação foi posta diante de uma grande contradição e, de essência articuladora, passou a ser legalmente responsável por realizar "pressões sobre os indivíduos, formalizadas pelas apreciações/ avaliações [...] contribuindo para a performatividade do grupo" (BALL, 2002, p. 11).

A função eminentemente articuladora e voltada para o exercício de atividades pedagógicas direcionadas às necessidades específicas das escolas foi apropriada com outros objetivos e intenções. Vinculando-se a formas tradicionais e burocráticas de administração escolar, embora disfarçadas em meio a um discurso convincente, a coordenação voltou-se para o controle e o monitoramento docente, assumindo múltiplas tarefas que alteraram sua natureza e identidade.

Ao alterar a natureza da função, as reformas recentes vincularam-na à realização de tarefas atreladas aos propósitos oficiais, evidenciando um distanciamento entre o que os professores esperavam e o que foi oferecido pelas medidas implementadas. Mais do que reformas técnico-estruturais, como indicado por Ball (2002), as reformas atuais reformaram professores e alteraram o significado do trabalho realizado.

A análise das resoluções apontou o aprimoramento das questões relativas ao controle do trabalho docente, controle este que passou a ser realizado por modos menos visíveis e mais sutis de regulação. Depois de avanços ocorridos na década de 1980, quando se vivenciou um forte movimento de democratização das escolas, percebemos um retrocesso em relação à organização do trabalho docente e às formas de gestão escolar na rede estadual.

Do ponto de vista legal, a apropriação da função de coordenação pedagógica pelas reformas é bem clara. Por outro lado, também é importante dizer que, se há, por um lado, a tentativa de cooptação dessa função de natureza pedagógica e democrática para a realização de um trabalho gerencial e performático, há a possibilidade de desenvolvimento de estratégias de resistência nas escolas. As escolas contam com a atuação social de sujeitos que, interpretando e reinterpretando as determinações oficiais, estabelecem cotidianamente estratégias de resistência diante do forte movimento de controle. Nesse sentido, temos um amplo campo para as pesquisas educacionais sobre a coordenação pedagógica. Ainda há muito a ser investigado sobre a atuação cotidiana do PCP e sua intersecção com as medidas oficiais. 


\section{Referências}

ALMEIDA, Laurinda Ramalho de. 0 coordenador pedagógico ante 0 desafio de articular e mobilizar a equipe escolar para tecer 0 projeto pedagógico. In: GUIMARÃES, Ana Archângelo et al. 0 coordenador pedagógico e a educação continuada. São Paulo: Loyola, 1998. p. 21-22.

BALL, Stephen J. Reformar escolas/reformar professores e os terrores da performatividade. Revista Portuguesa de Educação, Braga, v. 15, n. 2, p. 3-23, 2002.

Profissionalismo, gerencialismo e performatividade. Cadernos de Pesquisa, São Paulo, v. 35, p. 539-564, set./dez. 2005.

BARBOSA, Andreza. Os salários dos professores brasileiros: implicações para o trabalho docente. Brasília: Liber Livro, 2011.

BARROSO, João. Autonomia e gestão das escolas: que formação de professores? In: SEMINÁRIO: A TERRITORIALIZAÇÃO DAS POLÍTICAS PÚBLICAS EDUCATIVAS, 1998, Minho. Actas... Guimarães: Centro de Formação Francisco de Holanda, 1998. Disponível em: <http://www.cf-francisco-holanda.rcts.pt/public/acta2/acta2_8.htm>. Acesso em: 12 abr. 2008.

0 Estado e a educação: a regulação transnacional, a regulação nacional e a regulação local. In: (Org.). A regulação das políticas públicas de educação: espaços, dinâmicas e actores. Lisboa: Educa, 2006. p. 41-70.

BARROSO, João et al. A regulação interna das escolas: lógicas e actores. In: BARROSO, João (Org.). A regulação das políticas públicas de educação: espaços, dinâmicas e actores. Lisboa: Educa, 2006. p. 163- 190.

CAÇÃO, Maria Izaura; MENDONÇA, Sueli G. de Lima. "São Paulo faz escola?": contribuições à reflexão sobre o novo currículo paulista. In: GRANVILLE, Maria Antonia (Org.). Currículos, sistemas de avaliação e práticas educativas: da escola básica à universidade. Campinas: Papirus, 2011. p. 219-246.

CHRISTOV, Luiza H. da Silva. Sabedorias do coordenador pedagógico: enredos do interpessoal e de (con)ciências na escola. 2001, 162f. Tese (Doutorado em Psicologia da Educação) - Pontifícia Universidade Católica, São Paulo, 2001.

- Garota interrompida: metáfora a ser enfrentada. In: PLACCO, Vera M. N. de Souza; ALMEIDA, Laurinda Ramalho de

(Orgs.). 0 coordenador pedagógico e o cotidiano da escola. 2. ed. São Paulo: Loyola, 2004. p. 61-70.

CLEMENTI, Nilba. A voz dos outros e a nossa voz. In: ALMEIDA, Laurinda Ramalho de; PLACCO, Vera M. N. de Souza (Org.). 0 coordenador pedagógico e o espaço da mudança. São Paulo: Loyola, 2001. p. 53-66.

DIAS-DA-SILVA, Maria Helena G. F.; LOURENCETTI, Gisela do Carmo. A 'voz' dos professores e algumas reformas educacionais nas séries finais do ensino fundamental: desenvolvimento ou impasse? In: SAMPAIO, Maria M. Ferreira. 0 cotidiano escolar face às políticas educacionais. Araraquara: JM, 2002. p. 21-43.

DUARTE, Rita de Cássia. 0 professor coordenador das escolas públicas estaduais paulistas: análise das condiç̃os de trabalho e a construção do projeto político pedagógico. 2007, 133f. Dissertação (Mestrado em Educação Escolar) - Faculdade de Ciências e Letras. Universidade Estadual Paulista, Araraquara, 2007.

FERNANDES, Maria José da Silva. Problematizando o trabalho do professor coordenador pedagógico nas escolas públicas estaduais paulistas. 2004, 113f. Dissertação (Mestrado em Educação Escolar) - Faculdade de Ciências e Letras. Universidade Estadual Paulista, Araraquara, 2004.

A coordenação pedagógica em face das reformas escolares paulistas (1996-2007). 2008, 282f. Tese (Doutorado em Educação Escolar) - Faculdade de Ciências e Letras. Universidade Estadual Paulista, Araraquara, 2008.

. 0 professor coordenador pedagógico e a fragilidade da carreira. Estudos em Avaliação Educacional, v. 20, n. 44, p. $\overline{411-424}$, set./dez. 2009.

FRANCO, Francisco Carlos. 0 coordenador pedagógico e o professor iniciante. In: BRUNO, Elaine B. Gorgueira; ALMEIDA, Laurinda Ramalho de; CHRISTOV, Luiza H. da Silva (Orgs.). 0 coordenador pedagógico e a formação docente. São Paulo: Loyola, 2000. p. 33-36. 
FUSARI, José Cerchi. Formação contínua de educadores. 1997, 200f. Tese (Doutorado em Educação) - Faculdade de Educação, Universidade de São Paulo, São Paulo, 1997.

GIROUX, Henry A. Os professores como intelectuais: rumo a uma pedagogia crítica da aprendizagem. Porto Alegre: Artes Médicas, 1997. p. 157-164.

GUILHERME, Claudia C. Fiorio. A progressão continuada e a inteligência dos professores. 2002, 143f. Tese (Doutorado em Educação) - Faculdade de Ciências e Letras, Universidade Estadual Paulista, Araraquara, 2002.

MATE, Cecília Hanna. Qual a identidade do professor coordenador pedagógico. In: GUIMARÃES, Ana Archângelo et al. 0 coordenador pedagógico e a educação continuada. São Paulo: Loyola, 1998. p. 17-20.

OLIVEIRA, Dalila Andrade. As reformas educacionais e suas repercussões sobre o trabalho docente. In: educacionais na América Latina e os trabalhadores docentes. Belo Horizonte: Autêntica, 2003. p. 13-35. (Org.). Reformas

OLIVEIRA, Tamara F. Mantovani de. Escola, cultura do ideal e do amoldamento. São Paulo: Iglu, 2003. p. 13-130.

RODRIGUES, Jean Douglas Zeferino. Implicações do projeto "São Paulo faz escola" no trabalho de professores do ciclo I do ensino fundamental. 2010. 258f. Dissertação (Mestrado em Educação Escolar) - Faculdade de Ciências e Letras, Universidade Estadual Paulista, Araraquara, 2010.

RUSSO, Miguel Henrique. Trabalho e administração da escola: desenvolvimento e apropriação do sentido que assumem no processo de produção pedagógica. Revista Brasileira de Política e Administração da Educação, Recife, v. 27, n. 3, p. 493-516, 2011.

SAMPAI0, Maria das Mercês F.; MARIN, Alda Junqueira. Precarização do trabalho docente e seus efeitos sobre as práticas curriculares. Educação e Sociedade, Campinas, v. 25, p. 1203-1226, set./dez. 2004.

SÃO PAULO (Estado). Secretaria de Estado da Educação. Estatuto do Magistério. São Paulo, 1974.

Secretaria de Estado da Educação. Lei Complementar 201/78. São Paulo, 1979.

Secretaria de Estado da Educação. Estatuto do Magistério. São Paulo, 1985.

Secretaria de Estado da Educação. A escola de cara nova. São Paulo, 1996a.

Secretaria de Estado da Educação. Resolução SE nº 28/1996. Dispõe sobre o processo de seleção, escolha e designação de docente para exercer as funções de Professor Coordenador, em escolas da rede estadual de ensino e dá providências correlatas. São Paulo, 1996b. 1996c. p. 3-8.

Sindicato dos Professores do Ensino Oficial do Estado de São Paulo. Caderno de Formação. São Paulo, n. 0 (zero),

Secretaria de Estado da Educação. Resolução SE nº 76/1997. Dispõe sobre o processo de seleção, escolha e designação de docente para exercer as funções de Professor Coordenador, em escolas da rede estadual de ensino. São Paulo, 1997.

Secretaria de Estado da Educação. Resolução SE n 35/2000. Dispõe sobre o processo de seleção, escolha e designação de docente para exercer as funções de Professor Coordenador, em escolas da rede estadual de ensino e dá providências correlatas. São Paulo, 2000.

Secretaria de Estado da Educação. Resolução SE nº6/2006. Dispõe sobre o processo de seleção, escolha e designação de docente para exercer as funções de Professor Coordenador, em escolas da rede estadual de ensino. São Paulo, 2006.

Secretaria de Estado da Educação. Resolução SE nº 88/2007. Dispõe sobre a função gratificada de professor coordenador. São Paulo, 2007a.

Secretaria de Estado da Educação. Resolução SE n ${ }^{90 / 2007}$. Dispõe sobre função gratificada de professor coordenador nas quatro séries finais do Ensino Fundamental e no Ensino Médio, em escolas da rede estadual de ensino. São Paulo, 2007b. 
. Secretaria de Estado da Educação. Uma nova agenda para a educação pública. São Paulo, 2007c.

. Secretaria de Estado da Educação. Caderno do Gestor. São Paulo, 2008.

. Secretaria de Estado da Educação. Resolução SE nº 53/2010. Altera dispositivos da Resolução SE no 88/2007, e da Resolução SE no 21/2010, que dispõem sobre a função gratificada de professor coordenador. São Paulo, 2010.

TAMBERLINI, Angela R. M. de Barros. Os ginásios vocacionais: a dimensão política de um projeto pedagógico transformador. São Paulo: Annablume, 2001.

TEIXEIRA, Maria Cecília Sanchez. Política e administração de pessoal docente: um estudo sobre a Secretaria de Estado da Educação do Estado de São Paulo. São Paulo: Universidade de São Paulo, 1988. (Estudos e Documentos, v. 27)

Recebido em: 07.12.2011

Aprovado em: 07.05.2012

Maria José da Silva Fernandes é mestre e doutora em Educação Escolar pelo Programa de Pós-Graduação em Educação Escolar da Universidade Estadual Paulista "Júlio de Mesquita Filho", campus de Araraquara. Atualmente, é professora assistente doutora vinculada ao Departamento de Educação da Faculdade de Ciências da mesma instituição, campus de Bauru. 